\title{
The Effect of mechanical resistive loading on optimal respiratory signals and breathing patterns under added dead space and $\mathrm{CO} 2$ breathing
}

\author{
Shyan-Lung Lin ${ }^{1,2, a}$ and Hsing-Cheng Chang ${ }^{1}$ \\ ${ }^{1}$ Department of Automatic Control Engineering, Feng Chia University, 40724, Taichung, Taiwan \\ ${ }^{2}$ Department of Information Communication, MingDao University, 52345, Changhua, Taiwan
}

\begin{abstract}
Current study aims to investigate how the respiratory resistive loading affects the behaviour of the optimal chemical-mechanical respiratory control model, the respiratory signals and breathing pattern are optimized under external dead space loading and $\mathrm{CO} 2$ breathing. The respiratory control was modelled to include a neuro-muscular drive as the control output to derive the waveshapes of instantaneous airflow, lung volume profiles, and breathing pattern, including total/alveolar ventilation, breathing frequency, tidal volume, inspiratory/expiratory duration, duty cycle, and arterial $\mathrm{CO} 2$ pressure. The simulations were performed under various respiratory resistive loads, including no load, inspiratory resistive load, expiratory resistive load, and continuous resistive load. The dead space measurement was described with Gray's derivation, and simulation results were studied and compared with experimental findings.
\end{abstract}

\section{Introduction}

Among recently developed respiratory control models [1-6], possible optimality principle has found to be existed in the modeling of the respiratory control [6-8]. It was suggested that the normal ventilatory responses to chemical stimuli, exercise inputs, and mechanical loadings are predicted by the minimization of a controller objective function that consists of the total chemical and mechanical costs of breathing [8]. The hypothesis was later extended to model the integrative control of ventilatory responses and respiratory patterns, by expressing respiratory work rate of breathing in terms of the isometric respiratory driving pressure (instead of ventilation) [9]. Based on the optimal chemicalmechanical respiratory control model [8-9], a simulation platform initially implemented under MATLAB [10], was later revised using LabVIEW [11], to provide a realtime simulation tool for respiratory control, and a signal monitoring platform for instantaneous profiles and breathing pattern.

The problem concerning the nature and the function of the dead space is of basic importance for the full comprehension of the respiratory physiology and pathophysiology [12-18]. Extended studies [19-23] on the concept of dead space have been made in the last half-century. Gray [22] presented an analysis of the respiratory dead space problem with careful distinction drawn between measured anatomical dead space and calculated physiological (virtual) dead space. When a subject inhales a $\mathrm{CO}_{2}$ and air mixture, the ventilation increases, as does the concentration of $\mathrm{CO}_{2}$ in his blood and tissues. Tracheostomized ponies were utilized to determine the effect of reducing anatomical dead space on $\mathrm{P}_{\mathrm{aCO} 2}$ (arterial $\mathrm{CO}_{2}$ pressure) during $\mathrm{CO}_{2}$ inhalation. It was concluded [23] that the relationships of ventilatory responses did not differ between normal and decreased dead space cases with tracheostomy breathing. Experiments were conducted on healthy men [24] by adding dead space and $\mathrm{CO}_{2}$ inhalation to determine the ventilatory responses between rapid-eye-movement sleep and slow-wave sleep. The ventilatory response during external dead space breathing and $\mathrm{CO}_{2}$ inhalation were studied [25] for a given increase in $\mathrm{P}_{\mathrm{ETCO} 2}$ with different levels of $\mathrm{P}_{\mathrm{ETO} 2}$ in human subjects. The effect of positive and negative inspiratory pressure on respiration was investigated [26] both without and with an added external dead space, using either added inspiratory flow resistances or by providing inspiratory pressure support. The effects of different modes of airway $\mathrm{CO}_{2}$ load on the ventilation- $\mathrm{CO}_{2}$ output relationship were examined [27] during exercise with and without an external dead space.

Acute lung injury usually characterized with alveolar and capillary endothelial cell injuries, and that also results in compromised adequate pulmonary ventilation and blood flow across the lungs and increased $\mathrm{V}_{\mathrm{D}} / \mathrm{V}_{\mathrm{T}}$ [28]. This high dead space fraction generally symbolizes impaired ability to excrete $\mathrm{CO}_{2}$ and an increased risk of death in patients diagnosed with acute

\footnotetext{
a Corresponding author: sllin@,fcu.edu.tw, sllin@mdu.edu.tw
} 
respiratory distress syndrome [29]. The experiment [30], performed in hyperoxia with (IRL) and without (NL) an inspiratory resistive load $\left(15 \mathrm{~cm}-\mathrm{H}_{2} \mathrm{O} \cdot l^{-1} \cdot \mathrm{s}\right.$ at $\left.11 / \mathrm{s}\right)$ in healthy subjects, also depicted a similar $\dot{\mathrm{V}}_{\mathrm{E}}$ vs. $\mathrm{P}_{\mathrm{ETCO} 2}$ relationship.

Respiratory-mechanical factors [31] have been postulated to provide a further source of control for ventilatory response to moderate exercise. Experimental studies on the influence of inspiratory assistance on respiratory control have been conducted [31,30]. Poon et al. [33] examined the steady-state effects of expiratory resistive loading on the time course of inspiratory and postinspiratory muscle activities and ventilatory pattern during quiet breathing from five conscious human subjects. To identify the neural changes responsible for ventilatory compensation, the respiratory driving pressure waveform was calculated [34] during steadystate unloaded and loaded breathing in eight conscious normal subjects. The simulation of IRL can be performed by increasing $R_{\text {in }}$ (inspiratory airway) [35] from control (NL) with $\mathrm{R}_{\mathrm{ex}}$ (expiratory airway resistance) at no load, while ERL can be performed by increasing resistance in $R_{\text {ex }}$ with $R_{\text {in }}$ at no load [33, 36, 37]. To perform continuous resistive loading (CRL), the inspiratory and expiratory airway resistances $\left(\mathrm{R}_{\mathrm{in}}\right.$ and $\left.\mathrm{R}_{\mathrm{ex}}\right)$ are increased to the intended levels of loading. Brack [38] studied healthy subjects breathing at rest and with continuous inspiratory resistive loads applied randomly through flow resistors. With eight subjects, flow was recorded at rest [39], while breathing against inspiratory threshold loads and resistive loads, and while inhaling $7 \% \mathrm{CO}_{2}$.

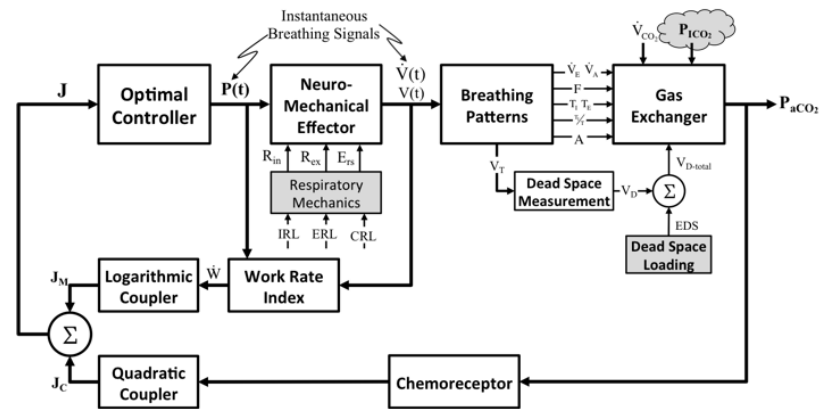

Fig. 1. The optimal chemical-mechanical respiratory control and simulation prospect.

\section{Optimal Respiratory Control Model}

Previous researches have successfully proposed and implemented a simulation strategy based upon a mathematical model of the optimal respiratory control with MATLAB and LabVIEW [11]. The model of the optimal chemical-mechanical respiratory control and simulation prospect of current study are illustrated in Fig. 1 . The controller is driven by both chemical and neuromechanical feedback signals. In the figure, this is demonstrated by the coupling of chemical cost $\mathrm{J}_{\mathrm{C}}$ and mechanical cost $\mathrm{J}_{\mathrm{M}}$, represented by the chemical feedback signal quadratic coupler and the work rate logarithmic coupler, respectively. The fundamental hypothesis of the model is that a total cost function can be formulated to reflect the balance of a combined challenge due to the chemical and mechanical cost of breathing [8]. The mathematical descriptions of these functional blocks depicted in Fig. 1 have been detailed in earlier reports [9-11] and are outlined below Eqs. (1) (7):

$$
\begin{gathered}
J=J_{C}+J_{M} \\
J_{C}=\alpha^{2} \cdot\left(P_{a c O_{2}}-\beta\right)^{2} \\
J_{M}=\ln \dot{W} \\
\dot{W}=\dot{W}_{I}+\dot{W}_{E} \\
\dot{W}_{I}=\frac{1}{T} \int_{0}^{T_{I}} \frac{P(t) \cdot \dot{V}(t)}{\xi_{1}^{n} \cdot \xi_{2}^{n}} d t \\
\left\{\begin{array}{l}
\xi_{1}=1-\frac{P(t)}{P_{\max }} \\
\xi_{1}=1-\frac{\dot{P}(t)}{P_{\max }}
\end{array}\right. \\
\dot{W}_{E}=\frac{1}{T} \int_{T_{I}}^{T} P(t) \cdot \dot{V}(t) d t
\end{gathered}
$$

In Eq. (4), the total mechanical index is assumed to be a weighted sum of the inspiratory and expiratory indexes, with a weighting parameter $\lambda$, and where $\dot{W}, \dot{W}_{I}$, $\dot{\mathrm{W}}_{\mathrm{E}}$, represent the total respiratory, inspiratory, and expiratory work rate in $\mathrm{kg} \cdot \mathrm{m} / \mathrm{sec}$, respectively. Efficiency factors $\xi_{1}$ and $\xi_{2}$ account for the effects of respiratory-mechanical limitation and the decrease in neuro-mechanical efficiency with increasing effort. The overall efficiency is dependent on two factors: the maximum isometric pressure $\left(\mathrm{P}_{\max }\right)$ and the maximum rate of rise in the isometric pressure $\left(\dot{\mathrm{P}}_{\max }\right)$. The respiratory period of a breathing cycle $\left(\mathrm{T}=t_{1}+t_{2}, \mathrm{sec}\right)$ accounts for the inspiratory $\left(t_{1}\right)$ and expiratory $\left(t_{2}\right)$ durations of neural activity, however, the parameter $T_{I}$ describes the duration of mechanical inspiratory, where the airflow flows into lung for inspiratory work of breathing.

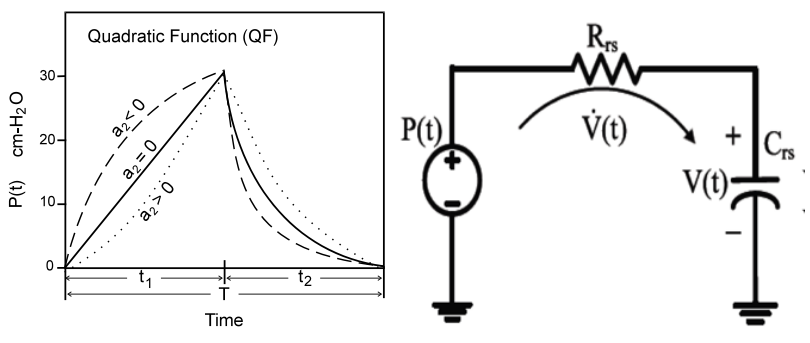

Fig. 2. Left: pressure waveshape over a complete respiratory cycle; Right: RC model of neuro-mechanical effector.

The neuro-mechanical effector relates the neural respiratory output to the resultant mechanical airflow and is required to optimize the neural input to the respiratory muscles for the optimization of the ventilatory airflow $(\dot{V}(t), 1 / \mathrm{min})$. The effector is described by the electrical RC model of Fig. 2(right) based on a lumped-parameter model for the relation between respiratory neural and mechanical outputs. In this model, the equation of motion is given by the following dynamic equation: 


$$
P(t)=\dot{V}(t) \cdot R_{r s}+V(t) \cdot E_{r s}
$$

The parameters $\mathrm{R}_{\mathrm{rs}}\left(\mathrm{cm}-\mathrm{H}_{2} \mathrm{O} \cdot 1^{-1} \cdot \mathrm{sec}\right)$ and $\mathrm{E}_{\mathrm{rs}}\left(=1 / \mathrm{C}_{\mathrm{rs}}\right.$, $\mathrm{cm}-\mathrm{H}_{2} \mathrm{O} / \mathrm{l}$ ) in Eq. (5) represent the total flow-resistive and volume-elastic components, respectively. These include the passive resistances and elastance of the lung, chest wall, and airways. The neuro-muscular driving pressure waveform $\left(\mathrm{P}(\mathrm{t}), \mathrm{cm}-\mathrm{H}_{2} \mathrm{O}\right)$ is modeled as inspiratory and expiratory phases, as were depicted in Fig. 2(left). The inspiratory pressure is approximated by a quadratic function, and the expiratory pressure is represented by an exponential discharge function of the form

$$
\begin{gathered}
P(t)=a_{0}+a_{0} t+a_{0} t^{2} \quad 0 \leq t \leq t_{1} \\
P(t)=P\left(t_{1}\right) \cdot e^{\frac{t-t_{1}}{\tau}} \quad t_{1} \leq t \leq t_{1}+t_{2}
\end{gathered}
$$

where the parameters $a_{0}$ and $a_{1}$ in Eq. (6) represent the net driving pressure and its rate of increase at the onset of the neural inspiratory phase respectively, and the parameter $a_{2}$ describes the shape of the wave; $t_{1}(\mathrm{sec})$ and $t_{2}(\mathrm{sec})$ represent the neural inspiratory and expiratory durations, respectively. In Eq. (7), $\mathrm{P}\left(\mathrm{t}_{1}\right)$ is the peak inspiratory pressure in units of $\mathrm{cm}-\mathrm{H}_{2} \mathrm{O}$ at the end of inspiration $\left(t_{1}\right)$, and $\tau$ denotes the rate of decline of inspiratory activity. With the mathematical description of Eqs. (5) (7) over a complete respiratory cycle, $\mathrm{T}=t_{1}+t_{2}$, the analytical solution for the instantaneous profile of the lung volume $(\mathrm{V}(\mathrm{t}), 1)$ over the functional residual capacity $(\mathrm{FRC}, 1)$ and airflow $(\dot{\mathrm{V}}(\mathrm{t}), 1 / \mathrm{s})$ within a breath can be obtained.

The plant of Gas Exchanger in Fig. 2 describes the events of the pulmonary exchange subject to the control signal $\dot{V}_{\mathrm{E}}$ (total ventilation, $1 / \mathrm{min}$ ), disturbances in the inhaled and metabolic $\mathrm{CO}_{2}\left(\mathrm{P}_{\mathrm{ICO} 2}\right.$, Torr, $\left.\dot{\mathrm{V}}_{\mathrm{CO}_{2}}, 1 / \mathrm{min}\right)$. The system's output is the pressures of arterial $\mathrm{CO}_{2}$ $\left(\mathrm{P}_{\mathrm{aCO} 2}\right.$, Torr). The gas exchanger equation describes the dependence of $\mathrm{P}_{\mathrm{aCO} 2}$ on the total ventilation and other disturbances:

$$
P_{a C O_{2}}=P_{a C O_{2}}+\frac{863 \cdot \dot{V}_{C O_{2}}}{\dot{V}_{E}\left(1-\frac{V_{D}}{V_{T}}\right)}
$$

where $\mathrm{P}_{\mathrm{aCO} 2}$ is assumed to be identical to the mean alveolar $\mathrm{P}_{\mathrm{CO} 2}$. Equation (8) describes the steady-state effect of ventilation on $\mathrm{P}_{\mathrm{aCO} 2}$ subject to any disturbances in the inhaled and metabolic production of $\mathrm{CO}_{2}$. To account for the changes in anatomic dead space with an airway caliber, the empirical relation [22] of Eq. (9) is employed:

$$
\begin{gathered}
V_{D}=0.037 \cdot V C \cdot\left(1+\frac{V_{T}}{8}\right) \\
V_{D-\text { total }}=V_{D}+E D S
\end{gathered}
$$

where $\mathrm{VC}$ is the vital capacity (l) and $\mathrm{V}_{\mathrm{T}}$ is the tidal volume (1), EDS is the imposed external dead space (1). Based on the optimized pressure profile of Eqs. (6) and (7), for any given respiratory resistance and elastance, the breathing patterns, including tidal volume $\left(\mathrm{V}_{\mathrm{T}}, 1\right)$, breathing frequency (f, bpm), total ventilation $\left(\dot{\mathrm{V}}_{\mathrm{E}}, 1 / \mathrm{min}\right)$, and alveolar ventilation $\left(\dot{\mathrm{V}}_{\mathrm{A}}, 1 / \mathrm{min}\right)$ can be obtained [11].

\section{Results and Discussion}

It is assumed that the parameters $\mathrm{R}_{\mathrm{rs}}$ and $\mathrm{E}_{\mathrm{rs}}$ of Eq. (5) represent the active resistance and active elastance, respectively, which include the effective impedance of the respiratory muscles. The normal load (NL) is defined to have respiratory resistance and elastance of $\mathrm{R}_{\mathrm{rs}}=3.02$ $\left(\mathrm{cm}-\mathrm{H}_{2} \mathrm{O} \cdot 1^{-1} \cdot \mathrm{s}\right)$ and $\mathrm{E}_{\mathrm{rs}}=21.9 \quad\left(\mathrm{~cm}-\mathrm{H}_{2} \mathrm{O} / \mathrm{l}\right) . \quad$ The inspiratory and expiratory resistances $\left(\mathrm{R}_{\mathrm{in}}\right.$ and $\left.\mathrm{R}_{\mathrm{ex}}\right)$ can be adjusted from the normal load condition to the intended values independently. In current study, the simulations were performed under various respiratory resistive loads, including no load, inspiratory resistive load (IRL, $\mathrm{R}_{\text {in }}=8 \mathrm{~cm}-\mathrm{H}_{2} \mathrm{O} \cdot \mathrm{l}^{-1} \cdot \mathrm{s}$ ), expiratory resistive load (ERL, $\mathrm{R}_{\mathrm{ex}}=8 \mathrm{~cm}-\mathrm{H}_{2} \mathrm{O} \cdot \mathrm{l}^{-1} \cdot \mathrm{s}$ ), and continuous resistive load $\left(\mathrm{CRL}, \mathrm{R}_{\mathrm{in}}=\mathrm{R}_{\mathrm{ex}}=8 \mathrm{~cm}-\mathrm{H}_{2} \mathrm{O} \cdot \mathrm{l}^{-1} \cdot \mathrm{s}\right)$.

In the resting state (Rest), $\mathrm{P}_{\mathrm{ICO} 2}$ is set to be $0 \%$ and $\dot{\mathrm{V}}_{\mathrm{CO}_{2}}$ is set to be $0.2(1 / \mathrm{min})$. In simulation Case-1, the $\mathrm{CO}_{2}$ inhalation was performed under various $\mathrm{CO}_{2}$ concentrations $\left(\mathrm{P}_{\mathrm{ICO}_{2}}=3\right.$ and $\left.5 \%\right)$. To investigate the effect of the imposed dead space on resultant respiratory signals and breathing patterns, the simulations of dead space loading were performed under with and without $\mathrm{CO}_{2}$ inhalation. Without $\mathrm{CO}_{2}$ inhalation, an external dead space (EDS) of 0.4 , and 0.8 (l) were added for Case-2. With $5 \%$ of $\mathrm{CO}_{2}$ inhalation, Case-3 was performed with an additional dead space loading of 0.4 (1). The respiratory parameter settings for the performed simulations are concluded in Table 1.

To examine the effect of various types of

\begin{tabular}{|c|c|c|c|c|c|c|c|c|}
\hline \multirow{2}{*}{\multicolumn{2}{|c|}{ Simulations }} & \multirow[b]{2}{*}{$\begin{array}{l}\dot{\mathrm{V}}_{\mathrm{CO}} \\
(1 / \mathrm{min}) \\
\end{array}$} & \multirow[b]{2}{*}{$\begin{array}{c}\mathrm{P}_{\mathrm{ICO} 2} \\
(\%)\end{array}$} & \multirow[b]{2}{*}{$\begin{array}{l}\text { EDS } \\
\text { (1) }\end{array}$} & \multicolumn{4}{|c|}{ Respiratory Mechanical Resistive Loadings } \\
\hline & & & & & NL & IRL & $\begin{array}{c}\text { ERL } \\
\left.{ }_{2} \mathrm{O} \cdot 1^{-1} \cdot \mathrm{s}\right)\end{array}$ & CRL \\
\hline Rest & & 0.2 & $0 \%$ & 0 & & & & \\
\hline \multirow{2}{*}{ Case-1 } & Case- $1-3 \%$ & 0.2 & $3 \%$ & & & & & \\
\hline & Case- $1-5 \%$ & 0.2 & $5 \%$ & & $\mathrm{R}_{\mathrm{in}}=3.02$ & $\mathrm{R}_{\mathrm{in}}=8$ & $\mathrm{R}_{\text {in }}=3.02$ & $\mathrm{R}_{\mathrm{in}}=8$ \\
\hline \multirow[t]{2}{*}{ Case-2 } & Case-2-0.4 & 0.2 & $0 \%$ & 0.4 & $\mathrm{R}_{\mathrm{ex}}=3.02$ & $\mathrm{R}_{\mathrm{ex}}=3.02$ & $\mathrm{R}_{\mathrm{ex}}=8$ & $\mathrm{R}_{\mathrm{ex}}=8$ \\
\hline & Case-2-0.8 & 0.2 & $0 \%$ & 0.8 & & & & \\
\hline Case-3 & & 0.2 & $5 \%$ & 0.4 & & & & \\
\hline
\end{tabular}
mechanical resistive loads on the optimized instantaneous respiratory waveforms under dead space loading and $\mathrm{CO}_{2}$ inhalation, Figure 3 depicts the profiles with Rest (upper left of Figure 3), Case-3 (upper right of

Table 1. Respiratory parameter setting for simulations 
Figure 3), Case-1-3\% (middle left of Figure 3), Case-1$\mathbf{5 \%}$ (middle right of Figure 3), Case-2-0.4 (lower left of Figure 3), and Case-2-0.8 (lower right of Figure 3). In the waveforms of each simulation case, three instantaneous respiratory signals, neural muscular driving pressure $\mathrm{P}(\mathrm{t})$ (first row), airflow $\dot{\mathrm{V}}(\mathrm{t}$ ) (second row), and lung volume $\mathrm{V}(\mathrm{t})$ (third row), were showed. On the other hand, three types of mechanical resistive loadings, IRL (first column), ERL (first column), and CRL (first column), were displayed to demonstrate the comparisons on optimized waveforms of loaded (dotted line) and normal load (solid line).

We found IRL generally resulted in higher amplitude of $\mathrm{p}(\mathrm{t})$ and $\mathrm{V}(\mathrm{t})$ with more concave upward, prolonged inspiratory duration $\left(t_{1}\right)$, and higher duty cycle $\left(\mathrm{T}_{\mathrm{I}} / \mathrm{T}\right)$ for the waveforms in Rest, Case-1s, and Case-3.
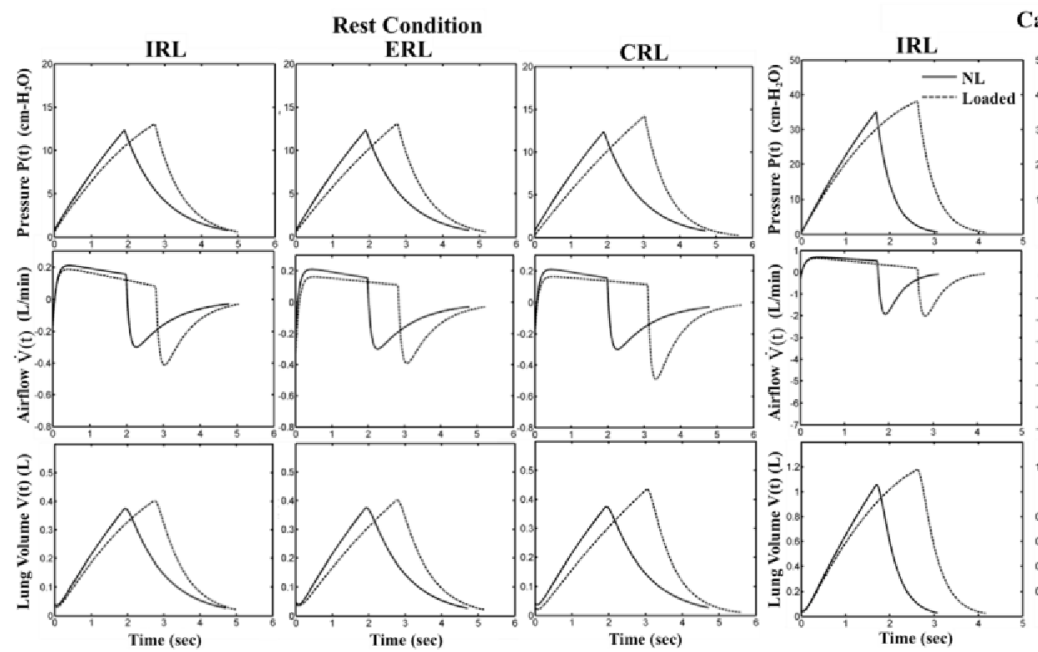

Case-3: $\mathrm{P}_{1 \mathrm{ICO}_{2}}=5 \%$ \& EDS $=0.4$

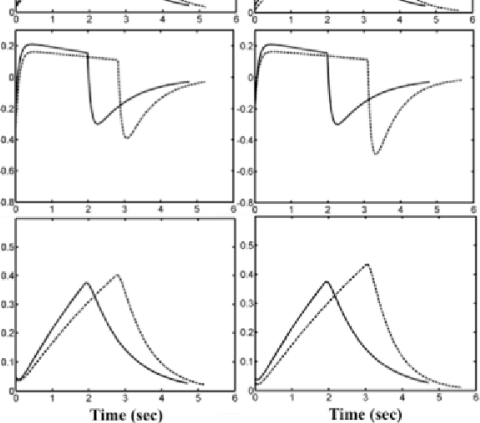

Case-1: $\mathrm{P}_{1 \mathrm{ICO}_{2}}=3 \%$
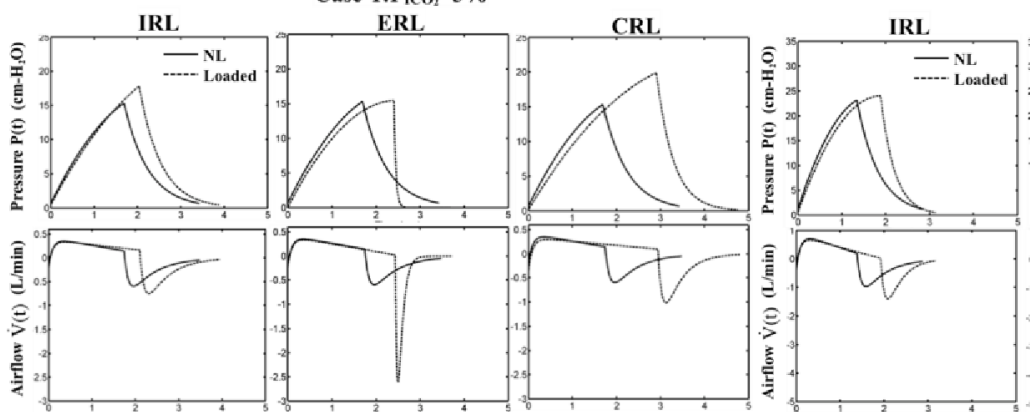

ERI

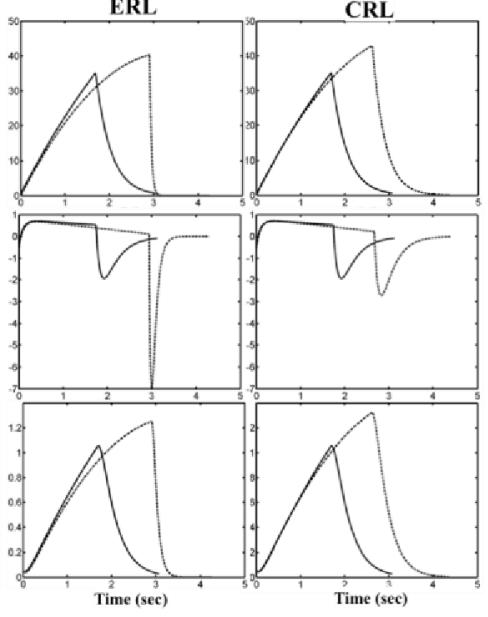

Case-1: $\mathrm{P}_{\mathrm{ICO}}=5 \%$
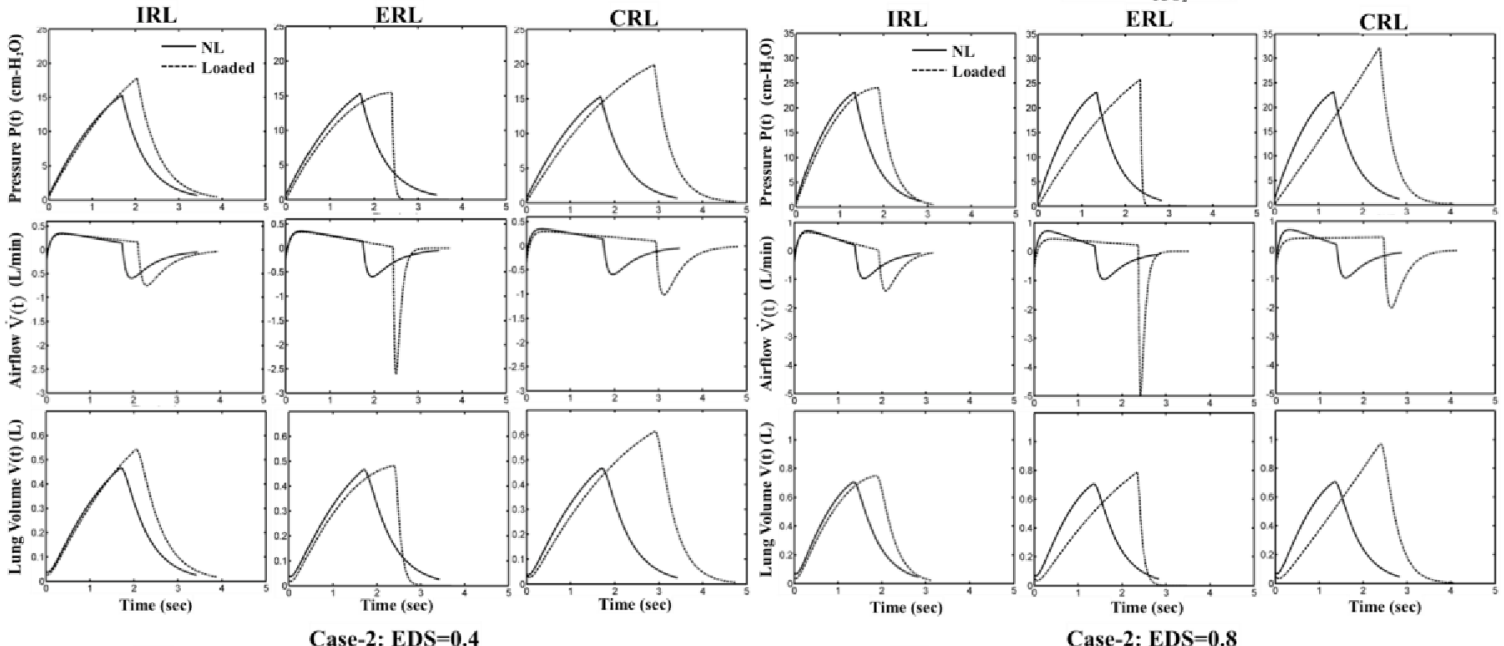

Case-2: EDS $=0.8$
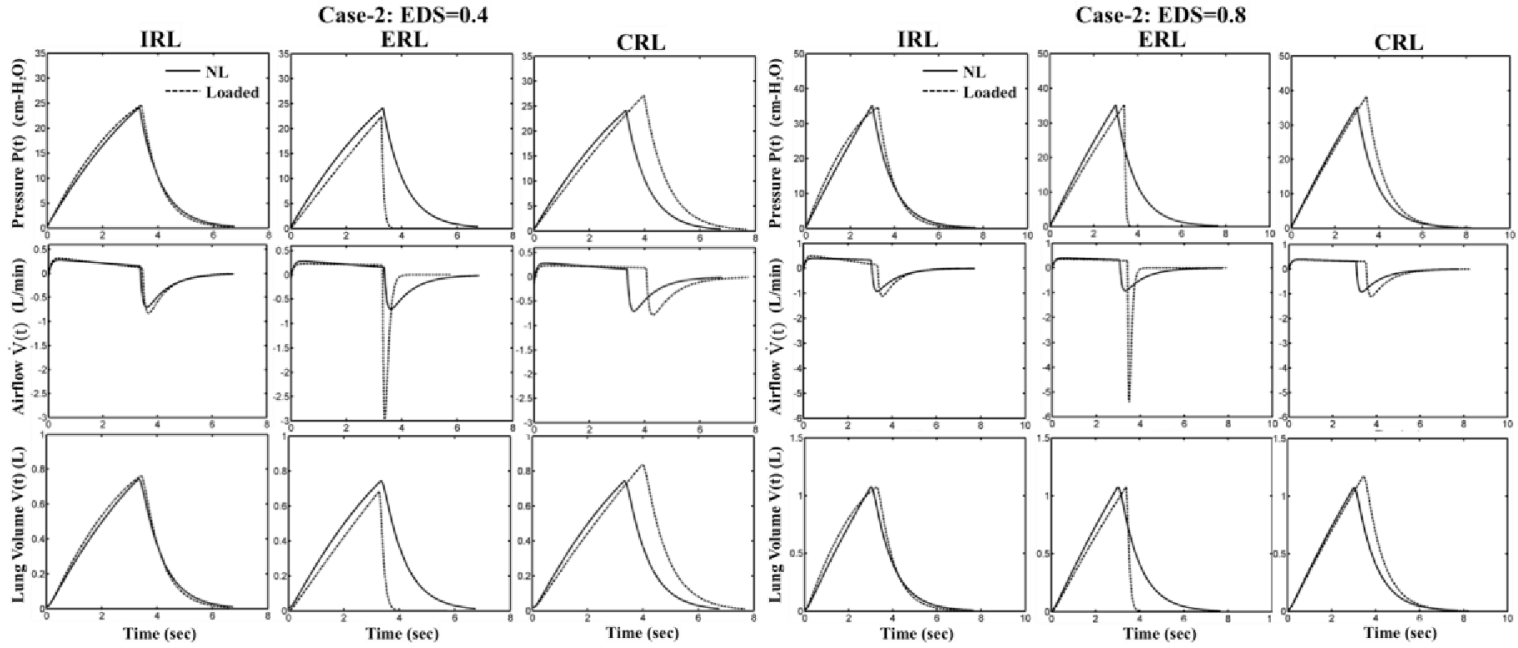

Fig. 3. Instantaneous respiratory signals, $\mathrm{P}(\mathrm{t}), \dot{\mathrm{V}}(\mathrm{t})$, and $\mathrm{V}(\mathrm{t})$, under various types of mechanical resistive loads. 
However, the imposed IRL did not show much effect on Case-2 as dead space loading was imposed. In resting condition, the mechanical loadings of ERL and CRL exhibited similar effect on the waveshapes of respiratory signals but with a elongated $t_{1}$ and consequently a higher peak amplitude in $\mathrm{P}(\mathrm{t})$ and $\mathrm{V}(\mathrm{t})$. During $\mathrm{CO}_{2}$ inhalation (Case-1-3\% and Case-1-5\%), EDS loadings (Case-20.4 and Case-2-0.8), and a combination of both (Case-3), an abruptly fall in the beginning of expiratory phases of $\mathrm{P}(\mathrm{t})$ were found and the peak flows in expiratory phase were significantly boosted during ERL in comparison with those of Rest.

As EDS loadings were imposed alone in Case-2-0.4 and Case-2-0.8, both IRL and ERL did not have much effect on the peaks of $\mathrm{P}(\mathrm{t})$ and $\mathrm{V}(\mathrm{t})$ at the end of inspiration as they did to the other simulation cases. However, in Case-3 with $\mathrm{P}_{\mathrm{ICO}_{2}}=0 \%$ and EDS $=0.4$ (1), three types of mechanical resistive loadings attained largest effect on the increasing of peak amplitudes on the neural muscular driving pressure, lung volume, and expiratory peak flow. As long as the waveforms of the $\mathrm{P}(\mathrm{t})$ and $\mathrm{V}(\mathrm{t})$ are concerned, the loading of CRL in all cases resulted in the most notable rises in amplitude in comparison with IRL and CRL did. Nevertheless, CRL appeared not to have much influence on the waveshapes of airflow except in Case-1-5\%, as higher concentration of $\mathrm{CO}_{2}$ was inhaled.

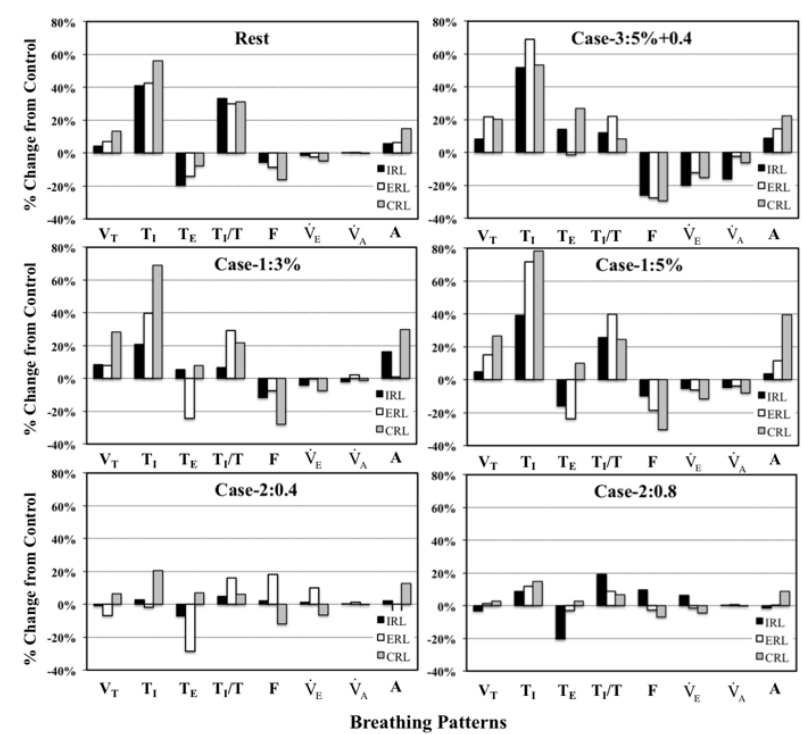

Fig. 4. Changes in breathing patterns under various types of mechanical resistive loads relative to control (normal load). $\mathrm{V}_{\mathrm{T}}$ : tidal volume; $\mathrm{T}_{\mathrm{I}}, \mathrm{T}_{\mathrm{E}}$ : inspiratory time, and expiratory time; $\mathrm{Ti} / \mathrm{T}$ : duty cycle; F: breathing frequency; $\dot{\mathrm{V}}_{\mathrm{E}}$ : minute ventilation; $\dot{\mathrm{V}}_{\mathrm{E}}$ : alveolar ventilation; A: peak amplitude of pressure.

The relative percentage changes of corresponding pattern variables were concluded in Figure 4 to examine the effect of various types of mechanical resistive loadings on model behavior. As shown in Figure 4, mechanical resistive loadings (IRL in dark; ERL in blank; CRL in gray) caused increases in $\mathrm{V}_{\mathrm{T}}$ during Rest and
$\mathrm{CO}_{2}$ inhalation (Case-1-3\%, Case-1-5\%, and Case-3). The effect of EDS loading on $\mathrm{V}_{\mathrm{T}}$ was not significant in both cases of Case-2. All mechanical loadings resulted in an increase in $T_{I}$, which is consistent with the experimental data $[33,34,38]$. The expiratory duration $T_{E}$ decreased in all cases of simulations during ERL while the effect of IRL remained ambiguous. However, $\mathrm{T}_{\mathrm{E}}$ for ERL exhibited more substantial increase in Case-1-3\%, Case-1-5\%, and Case-2-0.4\%. As a result of elongated $\mathrm{T}_{\mathrm{I}}$ during mechanical loading, the duty cycle generally increased in all cases, however, the effect of $\mathrm{CO}_{2}$ inhalation showed larger extent of increase in $\mathrm{T}_{\mathrm{I}} / \mathrm{T}$ than EDS loading did. In contrast to the increase in tidal volume, the breathing frequency $\mathrm{F}$ decreased during Rest and $\mathrm{CO}_{2}$ inhalation (Case-1-3\%, Case-1-5\%, and Case-3), and effect of EDS loading on F was not clear in both cases of Case-2. Consequently, the decrease in total ventilation $\dot{V}_{\mathrm{E}}$ displayed similar behavior as in breathing frequency for all simulations. No matter what type of mechanical loading was imposed, the alveolar ventilation $\dot{\mathrm{V}}_{\mathrm{A}}$ maintained nearly constant as in Rest during $\mathrm{CO}_{2}$ inhalation or EDS loading. In comparison with IRL and ERL, the CRL exhibited substantial increases on the peak amplitude (A) of neural muscular drive $\mathrm{P}(\mathrm{t})$ during all cases of simulation.

\section{Conclusions}

With a unified prediction of exercise and chemical responses was shown entirely in terms of conventional feedback-mechanisms based on the optimal chemicalmechanical respiratory control model, instead of using a separate stimulus signal, we use a human respiratory control model to simulate the effect of mechanical resistive loading on the optimized respiratory signals and breathing patterns. The simulations are performed in resting state, $\mathrm{CO}_{2}$ inhalation $\left(\mathrm{P}_{\mathrm{ICO}_{2}}=3\right.$ and $5 \%$ ), external dead space loading (EDS $=0.4$ and 0.8 1), and a combination of both $\left(\mathrm{P}_{\mathrm{ICO}_{2}}=5 \%\right.$ and $\left.\mathrm{EDS}=0.41\right)$. Various types of resistive loading, IRL, ERL, and CRL are imposed for the study of model behavior in comparisons with normal load. An earlier research [40] with the same model has explored the effect of the imposed dead space loading on the optimized respiratory profiles under increased levels of $\mathrm{CO}_{2}$ inhalation. It was concluded that higher amplitude with prolonged inspiratory duration and higher duty cycle were attained with $\mathrm{EDS}=0.4$ (1). The increase of EDS $=0.8$ (1) showed opposite effects on the inspiratory duration and duty cycle under $\mathrm{P}_{\mathrm{ICO}_{2}}=0 \%$ and $7 \%$. No significant change in the waveshapes of these respiratory profiles was found with the imposed dead space loading under $\mathrm{CO}_{2}$ inhalation.

In current study, the simulation results of successfully provided extended view into the respiratory 
signals, including neural muscular driving pressure, airflow, and lung volume, and breathing patterns. We found IRL generally resulted in higher amplitude of $\mathrm{p}(\mathrm{t})$ and $\mathrm{V}(\mathrm{t})$ with more concave waveshape, prolonged inspiratory duration and higher duty cycle $\left(T_{I} / T\right)$ for the waveforms. In comparison with those of resting state, an abruptly fall in the beginning of expiratory phases of $\mathrm{P}(\mathrm{t})$ were displayed and the peak flows in expiratory phase were significantly boosted with ERL during $\mathrm{CO}_{2}$ inhalation, EDS loadings, or a combination of both. The results of CRL in all cases exhibited the most notable rises in amplitude of pressure and lung volume in comparison with IRL and CRL, nevertheless, they also appeared not to have much influence on the waveshapes of airflow except in the case as higher concentration of $\mathrm{CO}_{2}$ inhalation.

We attained valuable results in simulations of mechanical resistive loadings on respiratory control with the optimal control model during imposed external dead space and $\mathrm{CO}_{2}$ inhalation. Further work can be extended to include the effects of mechanical elastic loading along with increased metabolic $\mathrm{CO}_{2}$ output. Recent evidences indicated that the increase in dyspnea and decrease in exercise tolerance is generally associated with the result of increases in physiological dead space and/or ventilator-perfusion mismatching [12-14]. The study of relative behavior of respiratory signals and comparative relationship of the ventilator responses between dead space loading and unloading during rest, $\mathrm{CO}_{2}$ inhalation, and exercise will provide further understanding of increases in central respiratory motor command output of human respiratory control, which is also associated with Dyspnea (respiratory discomfort) on exertion.

\section{Acknowledgement}

This study was granted by the Ministry of Science and Technology, Taiwan. (MOST 104-2221-E-451-005)

\section{References}

1. M.C. Khoo, R.E. Kronauer, K.P. Strohl, A.S. Slutsky, J. Appl. Physiol., 53 (1982).

2. M. Modarreszadeh, E.N. Bruce, J. Appl. Physiol., 76 (1994).

3. A. Rybak, M. Pottmann, B.A. Ogunnaike, J.S. Schwaber, Proc. of Am. Control Conf. (1995).

4. S. Mesic, R. Babuska, H.C. Hoogsteden, A.F.M. Verbraak, IEEE Trans. Biomed. Eng., 50 (2003).

5. G.D. Mitsis, Proc. of 9th International Conf. on Infor. Tech. and Appl. in Biomed. (2009).

6. H. Hirayama, Y. Shimizu, Y. Fukuyama, Proc. of 34th SICE Annual Conf., Sapporo (1995).

7. F.T. Tehrani, Proc. 20th Annu. International Conf. of the IEEE Eng. in Med. and Biol. Soc., 20 (1998).

8. C.S. Poon, J. Appl. Physiol. 62 (1987).
9. C.S. Poon, S.L. Lin, O.B. Knudson, J. Appl. Physiol. 72 (1992).

10. S.L. Lin, C.C. Chiu, J Biomed Eng. Appl. Basis Comm. 6 (1994).

11. S.L. Lin, N.R. Guo and C.C. Chiu, Modelling and simulation of respiratory control with LabVIEW, J. Med. Biol. Eng. 32 (2012): 51-60.

12. D.E. O'Donnell, R.B. Banzett, V. Carrieri-Kohlman, R. Casaburi, P.W. Davenport, S.C. Gandevia, A.F. Gelb, D.A. Mahler, K.A. Webb, Proc. Am. Thorac. Soc. 4 (2006).

13. D. Sajkov, N. Petrovsky, P. Palange, Curr. Opin. Support Palliat. Care, 4 (2010).

14. D. Jensen, D.E. O’Donnell, R. Li, Y.M. Luo, Respi. Physio. \& Neuro. 179 (2011).

15. M.N. Van der Plas, H.J. Reesnik, C.M. Roos, R.P. Van Steenwijk, J.J. Kloek, P. Bresser, Ann. Thorac. Surg. 89 (2010).

16. H.E. Wood, G.S. Mitchell, T.G. Babb, J. Appl. Physiol. 104 (2008).

17. C.S. Poon, J. Appl. Physiol. 105 (2008).

18. R.A. Klocke, J. Appl. Physiol. 100 (2006).

19. J.R. Pappenheimer, A.P. Fishman, L.M. Borrero, J. Appl. Physiol. 4 (1952).

20. R.L. Coon, J.P. Kampine, J. Appl. Physiol. 51 (1981).

21. C.B. Wolff, R.C. Garratt, J. Appl. Physiol. 53 (1982).

22. J.S. Gray, F.S. Groadins, E.T. Carter, J. Appl. Physiol. 9 (1956).

23. H.V. Forster, J. Appl. Physiol. 61 (1986).

24. A. Warley, Respir. Physiol. 75 (1989).

25. R. Maruyama, Jpn. J. Physiol. 38 (1988).

26. F. Lofaso, D. Isabey, H. Lorino, P. Scheid, Physiol. 89 (1992).

27. C.S. Poon, J. Appl. Physiol. 73 (1992).

28. U. Lucangelo, L. Blanch, Intensive Care Med. 30 (2004)

29. T.J. Nuckton, J.A. Alonso, R.H. Kallet, B.M. Daniel, J.F. Pittet, M.D. Eisner, Matthay A, N. Eng. J. Med. 346 (2002).

30. D.A. Sidney, C.S. Poon, J. Appl. Physiol. 78 (1995).

31. C.S. Poon, S.A. Ward, B.J. Whipp, J. Appl. Physiol. 62 (1987).

32. C.G. Gallagher, R. Sanii, M. Younes, J. Appl. Physiol. 66 (1989).

33. C.S. Poon, M. Younes, C.G. Gallagher, J. Appl. Physiol. 63 (1987).

34. V.I. Hof, P. West, M. Younes, J. Appl. Physiol. 60 (1986).

35. C.S. Poon, J. Appl. Physiol. 66 (1989).

36. L. Fee, R.M. Smith, M.B. English, J. Appl. Physiol. 83 (1997).

37. W.H. Thompson, P. Carvalho, J.P. Souza, N.B. Charan, J. Appl. Physiol. 89 (2000).

38. T. Brack, A. Jubran, M.J. Tobin, Am. J. Respir. Crit. Care Med. 157 (1998).

39. Z. Samara, M. Raux, M.N. Fiamma, A. Gharbi, S.B. Gottfried, C.S. Poon, T. Similowski, C. Straus, Respi. Physiol. \& Neuro. 165 (2009).

40. S.L. Lin, T.C. Chen, H.C. Chang, Int. Appl. Sci. and Prec. Eng. Conf. (ASPEC2013), (2013). 